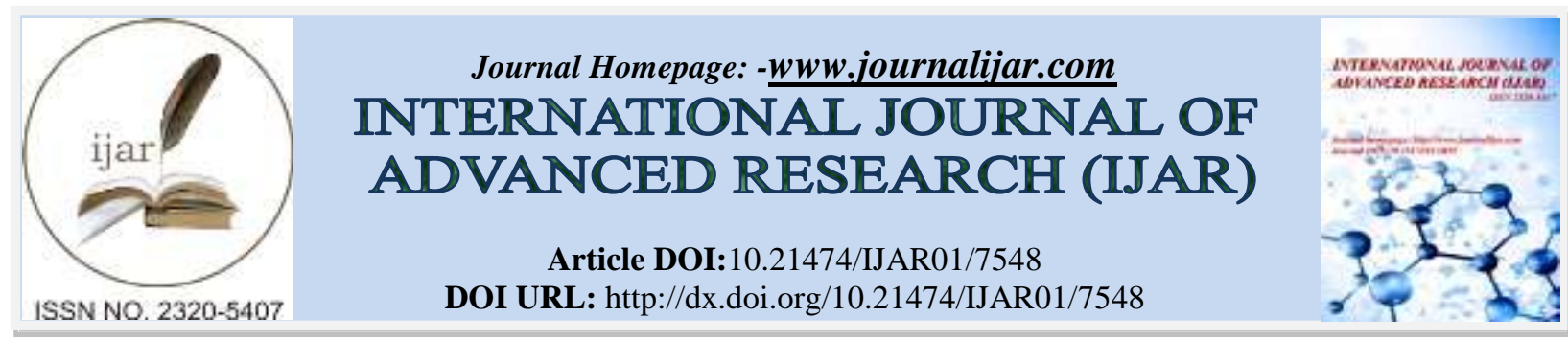

RESEARCH ARTICLE

\title{
USING DEMONSTRATION METHOD TO IMPROVE BASIC STAGE TWO PUPILS PERFORMANCE ON THE TOPIC "SIMPLE ELECTRONIC CIRCUIT" AT JUABEN PRESBYTERIAN PRIMARY SCHOOL.
}

\author{
Humphrey Darkeh Assem ${ }^{1}$, Laud Teye Nartey ${ }^{2}$, Kennedy Ameyaw Baah ${ }^{1}$ and Yin Annafo ${ }^{1}$ \\ 1. Science Department, Wesley College of Education, Kumasi-Ghana. \\ 2. Science Department, OLA College of Education, Cape Coast-Ghana.
}

\section{Manuscript Info}

Manuscript History

Received: 12 June 2018

Final Accepted: 14 July 2018

Published: August 2018

Keywords:-

Demonstration method, Electronic circuit, Teaching methods

\begin{abstract}
The purpose of the study was to find out the effect of using demonstration method to improve basic stage two pupils performance on the topic building a simple electronic circuit at Juaben Presbyterian primary school.

The data for the study was collected using test and interview. A sample size of twenty eight pupils was drawn from the population for the study through the simple random sampling technique. Simple percentage on the frequency distribution table of the scores enabled successful analysis of the data obtained. Results obtained from the analysis indicate that the use of demonstration method in the teaching of natural science topics particularly "simple electronic circuit" is very effective at the basic school level. It was recommended among other things that the ministry of education and for that matter the Ghana education Service (GES) should organize in- service educational programs for primary school teachers so that they will be able to teach natural science and integrated science effectively.
\end{abstract}

Copy Right, IJAR, 2018,. All rights reserved.

\section{Introduction:-}

Teaching methods are standard procedures that are employed in presentation of facts, idea, attitudes and skills to a learner or a group of learners (Assem, 2010). There are many teaching methods of teaching science such as activity method, discovery method, discussion method, demonstration method, role play, brainstorming, lecture, field trip laboratory and question and answer method. But in this study the researcher seek to use the demonstrations method of teaching.

A demonstration method involves showing, telling and doing something which can be observed by a group of learners. Thus, a teacher may demonstrate how to do something to his/her students in a practical lesson in a class. In demonstration, the teacher is the principal performer whiles the learners are his/her audience.it is usually the major part of all the learning activities which facilitates learning by doing. Demonstration often occurs when students have a hard time in connecting theories to actual practice.

In basic two, natural science syllabus has a number of challenging topics which pupils find difficult to understand. Among these topics is the topic "'Energy transformation'. 
Asiedu (2000) asserted that electronic circuit is the electrical path in which current travels. There are two types of circuit these are the opened and the closed circuit. A circuit is said to be open when the switch is put off such that the circuit becomes incomplete and hence no current flow through it. However a closed circuit becomes complete and hence there is a flow of current through the circuit.

A simple circuit has the following components:-

1. An electric source (energy) for example dry cell.

2. A load example resistor, capacitor, inductor or a combination of a switch and conducting materials.

3. LED (light emitting diode) or bulb.

4. Connecting wires

There is also an electronic circuit which is used to convert electrical energy into light energy or sound energy.

A simple electronic circuit has the following components or parts.

1. An electric source (energy)

2. A load (resistor)

3. A small speaker (earphone)

4. LED (light emitting diode) or bulb.

5. A switch and conducting material

6. Connecting insulating wires.

\section{Statement of the problem:-}

One of the expectations of education in Ghana is to gear towards improvement of pupils' participation in science. Science is described as the backbone of every developed country. Pupils are expected to acquire psychomotor skills like manipulation of equipment, eye hand co-ordination and measurement as they engage in demonstration lessons.

However during the supervision period of a student teacher, we observed a lesson on the topic '"energy transformation". We realized that pupils were not able to interpret conversion of one form energy to another. For example, transformation of electric energy to light energy as in the case of the torchlight bulb when it is switched on. It was also observed that about eighty percent of the pupils performed very badly in the exercise after the lesson.

We followed it up to interview the pupils to find out why they did not understand the lesson.

From the interview, we discovered that lack of teaching and learning materials and teaching methods were the major causes of pupils' inability to understand the lesson. This has necessitated the need to find out the use of demonstration method to improve basic stage two pupils performance on the topic building a simple electronic circuit at Juaben Presbyterian primary school.

\section{Purpose of the study:-}

The purpose of the study was to find out the effect of using demonstration method to improve basic stage two pupils performance on the topic building a simple electronic circuit at Juaben Presbyterian primary school.

\section{Research Questions:-}

The study was guided by the following:

1. What are causes of pupils' inability to construct simple electronic circuit to transform electrical energy to light energy?

2. What activities can help to improve the performance in the topic energy transformation?

\section{Review of Related Literature:-}

\section{Basic Concept of Electrical Circuit:-}

There is a connection between the arrangement of elements for conversion, transmission and storage of energy. Energy enters a circuit via one or more sources and leaves via one or more sinks. In the source energy is converted from mechanical, chemical and electromagnetic form. In the sink, the reverse process takes place. The source and sinks are linked by elements capable of transmitting and store electrical energy.

The familiar barred-operated flash lamp serves as a reminder of the energy flow processor in a circuit. In this device, energy is converted from chemical to electrical form in the battery and transmitted along wires to the lamp where 
most of the energy is converted into heat. A small but useful portion is omitted in the form of electromagnetic radiation.

In an electrical circuit energy is conveyed through the agency of electrical charge and through the medium of electric and magnetic field. An essential feature of any circuit is the transportation or charges. The rate at which charges show is referred to as the current. The greater the current the greater energy transmitted between the source and sinks. A charge is set in motion by the action of the electric field established throughout the circuit by the source. The field provides the electromotive force (EMF) which drives charges around the conducting path in the circuit. The flow to charge established a magnetic field.

Transmission of electrical energy is therefore made possible in a circuit by the presence of both electric and magnetic field in addition to the movement of change. The establishment of a field in a circuit leads to an expenditure of energy which is stored within the region of space occupied by the field. The electrical characteristics of a circuit may therefore be described generally by means of three elemental properties which are the resistance, capacitance, and inductance. Practical circuit consists of inter connected assemblies of components: resistors, capacitors and inductors each designed to exhibit one elemental property to the exclusion of the others. It is however, impossible to manufacture a component exhibiting a single property in pure form.

\section{Important Parts of a Simple Electrical Circuit:-}

The source is the energy source and produces the current which may be direct or alternating current. The load converts electric as energy into the form of energy needed by the component. For example, in the fan electrical energy is convert energy into motion (kinetic) and in the refrigerator it is converted energy into coldness (removal of heat). The conducting materials have the path through which electric energy generated, circulate and distributed among the needed components.

\section{Series and parallel connections of cells and bulbs:-}

According to Abott (2000), arrangement of cells is into two forms. These are series and parallel connections. A cell is said to be connected in series if the positive terminals of one cell is connected to the negative terminal or the other. For cell in series the same current flows through them and the individual voltage of the cells sum up tithe combined voltage, they give a brighter light dye to higher voltage generated.

\section{Electrical circuit with cells in series:-}

Materials needed for electrical circuit with cells in series are:

1. A piece of wooden board (about $24 \mathrm{~cm} \times 24 \mathrm{~cm}$ ).

2. Aluminum strip $(1 \mathrm{~cm} \times 1 \mathrm{~cm})$ as battery holder.

3. Aluminum foil.

4. One bottle top or match box, to be used as bulb holder.

5. Paper clips.

6. Nail

7. Insulated copper wire.

8. LED(bulb)

9. Drawing pins

10. Four dry cells.

\section{Procedure:-}

1. Bend each strip of aluminum into an ' $L$ " shape and nail it into the wooden board or nail two pieces of wood to the drawing board to fit the number of dry cells to be used .

2. Place the dry cells to follow each other (in series) between the piece of wood or the aluminum strip so that the positive end or poles of one is in contact with the negative end or pole of the other.

3. Make a hole in the bottle top.

4. Connect a wire to the base of the LED or bulb with two loose ends.

5. Fit the LED into the hole of the bottle top making sure the two loose ends of the wire comes out of thebottle top.

6. Nail the bottle top with the LEDonto the board ensuring that the LED sits on the piece of the aluminum foil.

7. Use drawing pins and paper clips to make a switch.

8. Connect the wire to make a circuit. 


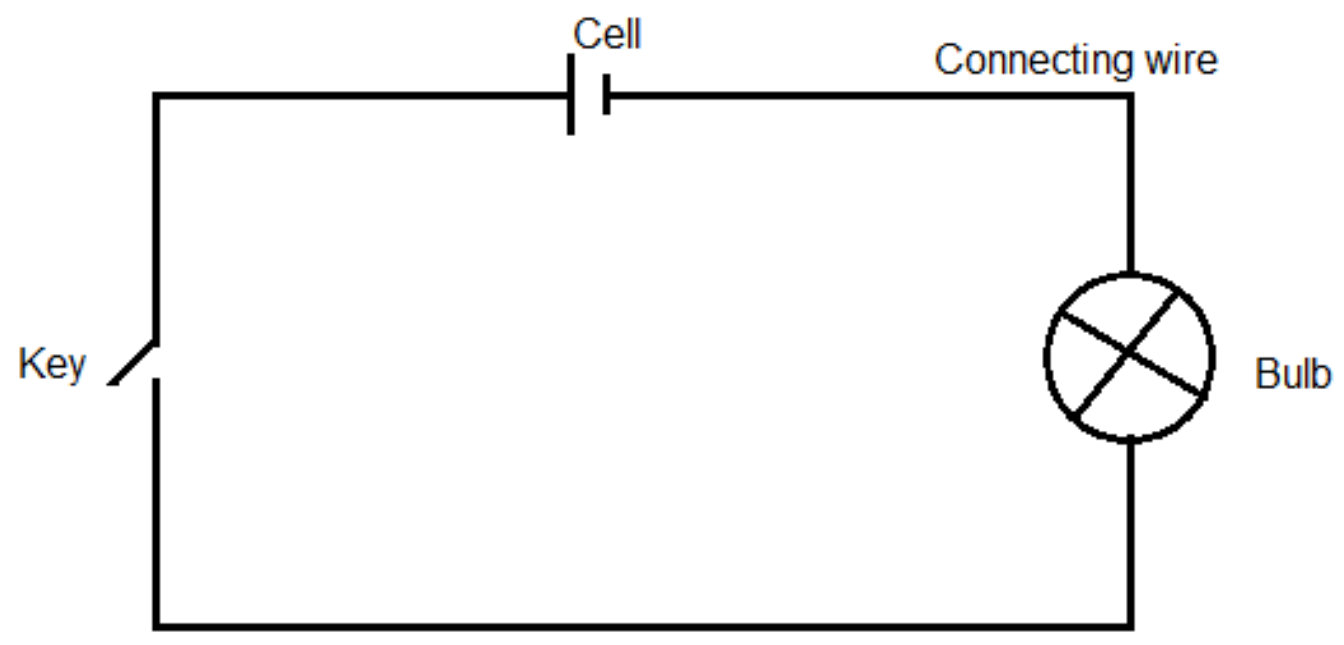

Fig. 1: Simple electric curcuit

\section{Arrangement of cells in parallel:-}

A cell is said to be connected in parallel if the positive terminals of the other cell and its negative terminal is also connected to the negative terminal of the other cell. For a parallel combination the current is shared among the cell and the resulting voltage equals to the voltage of one of the cells provided the cells have the voltage.

According to Aseidu (2005), materials needed for electrical current with cell in parallel are:

1. A piece of wooden board (about $24 \mathrm{~cm} \times 24 \mathrm{~cm}$ ).

2. Aluminum strip $(1 \mathrm{~cm} \times 1 \mathrm{~cm})$ as battery holder.

3. Aluminum foil.

4. One bottle top or match box, to be used as bulb holder.

5. Paper clips.

6. Nail

7. Insulated copper wire.

8. Led (bulb)

9. Drawing pins

10. Four dry cells.

\section{Procedure:-}

1. 1.Bend each strip of aluminum into an " $L$ " shape and nail it into the wooden board or nail two pieces of wood to the drawing board to fit the number of dry cells to be used .

2. Place the dry cells alongside in parallel so that similar poles or ends face one direction.

3. Make a hole in the bottle top.

4. Connect a wire to the base of the LED or bulb with two loose ends.

5. Fit the LED into the hole of the bottle top making sure the two loose ends of the wire comes out of the bottle top.

6. Nail the bottle top with the LED onto the board ensuring that the LED sits on the piece of the aluminum foil.

7. Use drawing pins and paper clips to make a switch.

8. Connect the wire to make a circuit.

\section{Building a Simple Electronic Circuit:-}

According to Folivi and Goodman (2001) electronic circuit is acircuit which is used to convert electrical energy into light energy or sound energy.

Materials needed to build a simple electronic circuit are:

1. Two dry cells(battery)

2. A switch

3. A resistor

4. A small speaker or earphone

5. A led (bulb) 
6. A piece of wooden board $(24 \mathrm{~cm} \times 24 \mathrm{~cm})$

7. Aluminum strips of pieces of wood $(1 \mathrm{~cm} \times 1 \mathrm{~cm})$ as battery holder

8. Aluminum foil

9. Bottle tops

10. Paper clips

11. Drawing pins

12. Nails

13. Insulating copper wire.

\section{Procedure:-}

1. Bend each strip of aluminum into ' $L$ '" shape or nail two pieces of wood to the drawing board to fit the number of dry cells to be used.

2. Place the dry cells to fit the aluminum strips or nailed pieces of wood.

3. Make a hole in each of the bottle tops.

4. Connect a wire to the base of the resistor with two loose ends.

5. Fit the resistor into the holes of the bottle top making sure that the loose ends of the wire comes out of the bottle top

6. Nail the bottle tops with the resistor onto the board ensuring that the resistor sit on the piece of aluminum foil

7. Use drawing pins or paper clips to make a switch

8. Connect the wires to make a series circuit with the earphone in the small speaker

9. Connect the LED (bulb) parallel with the earphone on to the small speaker.

10. Finally connect the LED in series with the earphone on the small speaker close and open the switch repeatedly and note what happen.

\section{Methodology:-}

The researcher used is action research. The target population was pupils in JuabenPresby Primary School. Basic two pupils were purposively sampled for the study and the sample size was 30 . The research procedure consisted of preintervention, intervention and post-intervention stage and interview.

At the pre-intervention stage, a pre -test was administered by the researchers during the instructional period in natural science under the section energy. This was done to find out the level of pupils knowledge in the topic simple electronic circuit. The test was made up of ten questions which were of two sections. That is section A and section B also contains four questions. The section A had options for pupils to choose the correct answers from. In section B, the pupils were to write down the parts of simple electronic circuit. The time limit that was allowed was thirty minutes. The result was not encouraging.

At the intervention stage, the intervention was administered by the researchers two weeks after the pre- test was conducted. The researchers prepared a sixty minute lesson plan with teaching and learning materials which were used (dry cells, bulb, a speaker, switch and insulated copper wire). The intervention lasted for one week, the meaning of electrical circuit, how to construct and draw cells connected in series and in parallel were taught. Lastly the interpretation of series and parallel connections were taught.

At the post intervention stage, post intervention was administered by the researcher two days after the intervention. The researcher used demonstration method as well as discussion method in teaching the pupils. The essence of the post test was to find out whether the pupils have been able to alleviate their problem in building a simple electronic circuit. The questions that were given to the pupils were strictly supervised by the researcher. The questions were scored over twenty (20) marks. The time allows was the same as the time for the pre test.

\section{Results/Discussion:-}

Research question 1: -

What are the causes of pupil's inability to construct a simple electronic circuit to transform electrical energy to sound energy. The result is presented in table 1 . 
Table 1:-Causes of pupils inability to construct a simple electronic circuit to transform electrical energy to sound energy

\begin{tabular}{|c|c|c|}
\hline ITEM & $\begin{array}{l}\text { YES } \\
\text { FREQ }(\%)\end{array}$ & $\begin{array}{l}\text { NO } \\
\text { FREQ }(\%) \\
\end{array}$ \\
\hline $\begin{array}{l}\text { Do you have enough science teaching and learning } \\
\text { materials in your school? }\end{array}$ & $2 .(7.2)$ & $2.692 .8)$ \\
\hline $\begin{array}{l}\text { Do you understand when your teacher teaches you } \\
\text { science? }\end{array}$ & $5(17.9)$ & $23(82.1)$ \\
\hline $\begin{array}{l}\text { Does your teacher relate what he teaches to your } \\
\text { personal experience? }\end{array}$ & $2(7.2)$ & $26(92.8)$ \\
\hline
\end{tabular}

From table 1:- it was indicated that twenty six pupils' represents $92.8 \%$ out of the twenty -eight pupils said that they do not have enough science teaching leaning materials at the school. Two pupils representing $7.2 \%$ out of the twenty eight pupils said that they have enough science learning materials in the school. Five pupils' representing $17.9 \%$ also said that they understand when their teacher teaches them science. Twenty three pupils' representing $82.1 \%$ said that their does not relate what he teaches with their personal experience. Twenty six pupils representing $92.8 \%$ said that their teacher does not relate what he teacher to their practical experience. Two pupils' representing $72 \%$ said that their teacher relate what he teaches to their personal experience.

The causes of pupil's inability to construct a simple electronic circuit to transform electrical energy to sound energy are lack of science equipment for practical lessons and also the teacher does not relate what he teaches to pupils' practical experience.

Research question 2. What activity can help to improve pupils' performance on the topic "energy transformation".

Table 2:-Results of pupils on activities that can help to improve pupils performance on the topic "energy transformation".

\begin{tabular}{|l|l|l|}
\hline Scores intervals & Yes & No \\
& Freq $(\%)$ & Freq $(\%)$ \\
\hline $0-2$ & 9 & 33.1 \\
$4-6$ & 12 & 42.9 \\
$8-10$ & 7 & 25.0 \\
$12-16$ & 0 & 0.0 \\
$18-20$ & 0 & 0.0 \\
\hline Total & 28 & 100 \\
\hline
\end{tabular}

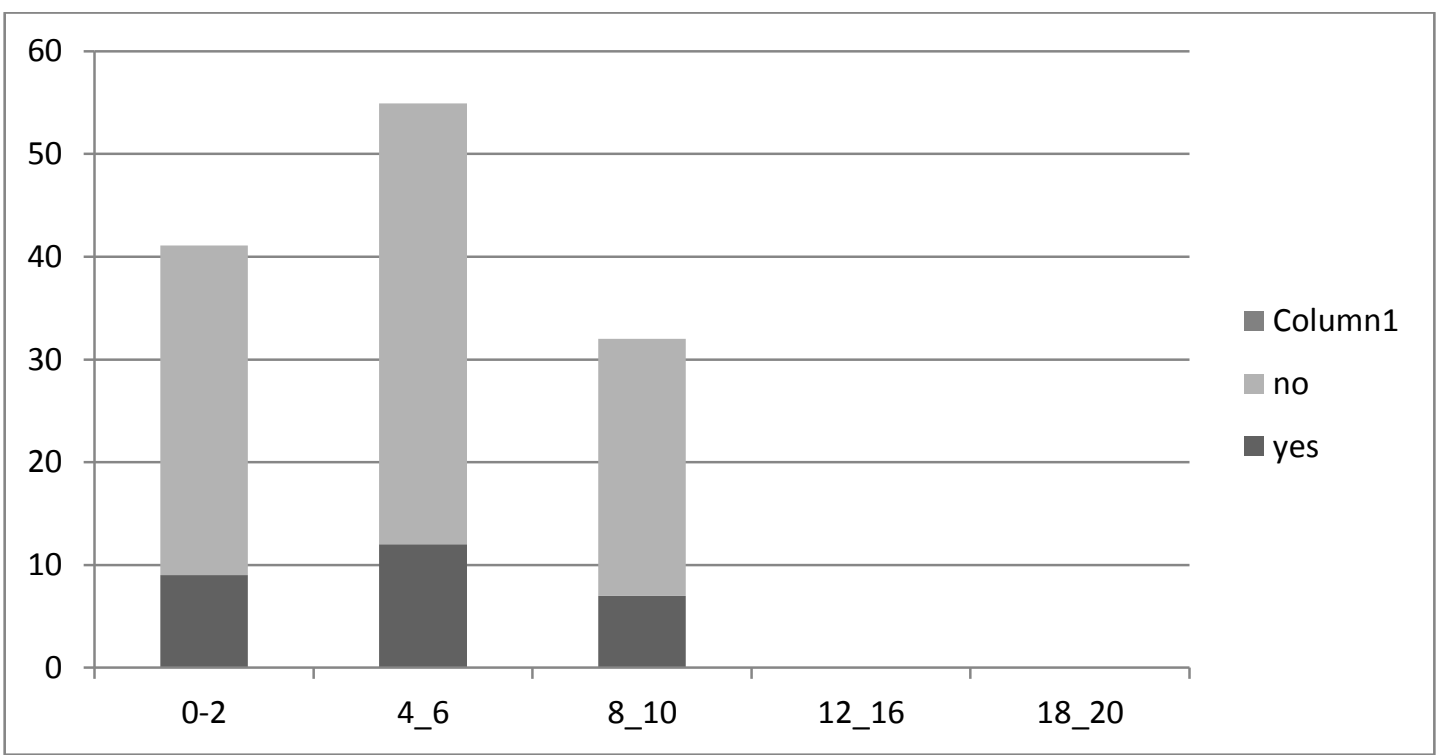

Table 2:- represents the distribution of pupils score in both section A and B questions for the pre-test. 
Twenty eight pupils representing $100 \%$ total part in the test. From the table it could be seen that twelve pupils representing $42.9 \%$ scores the range $8-10$. No pupils scored in the range 12-16 and 18-20 respectively. The detail results and sample of pupils work in pre-test could be found in appendix D.

Table 3 represents the pupils' performance on the post-test intervention

Table 3:-Pupils' performance on the post-test

\begin{tabular}{|l|l|l|}
\hline SCORES INTERVAL & YES & NO \\
& FREQ $(\%)$ & FREQ $(\%)$ \\
\hline $0-2$ & 0 & 0.0 \\
406 & 0 & 0.0 \\
$8-10$ & 4 & 14.3 \\
$12-16$ & 13 & 46.4 \\
$18-20$ & 11 & 39.3 \\
\hline Total & 28 & 100 \\
\hline
\end{tabular}

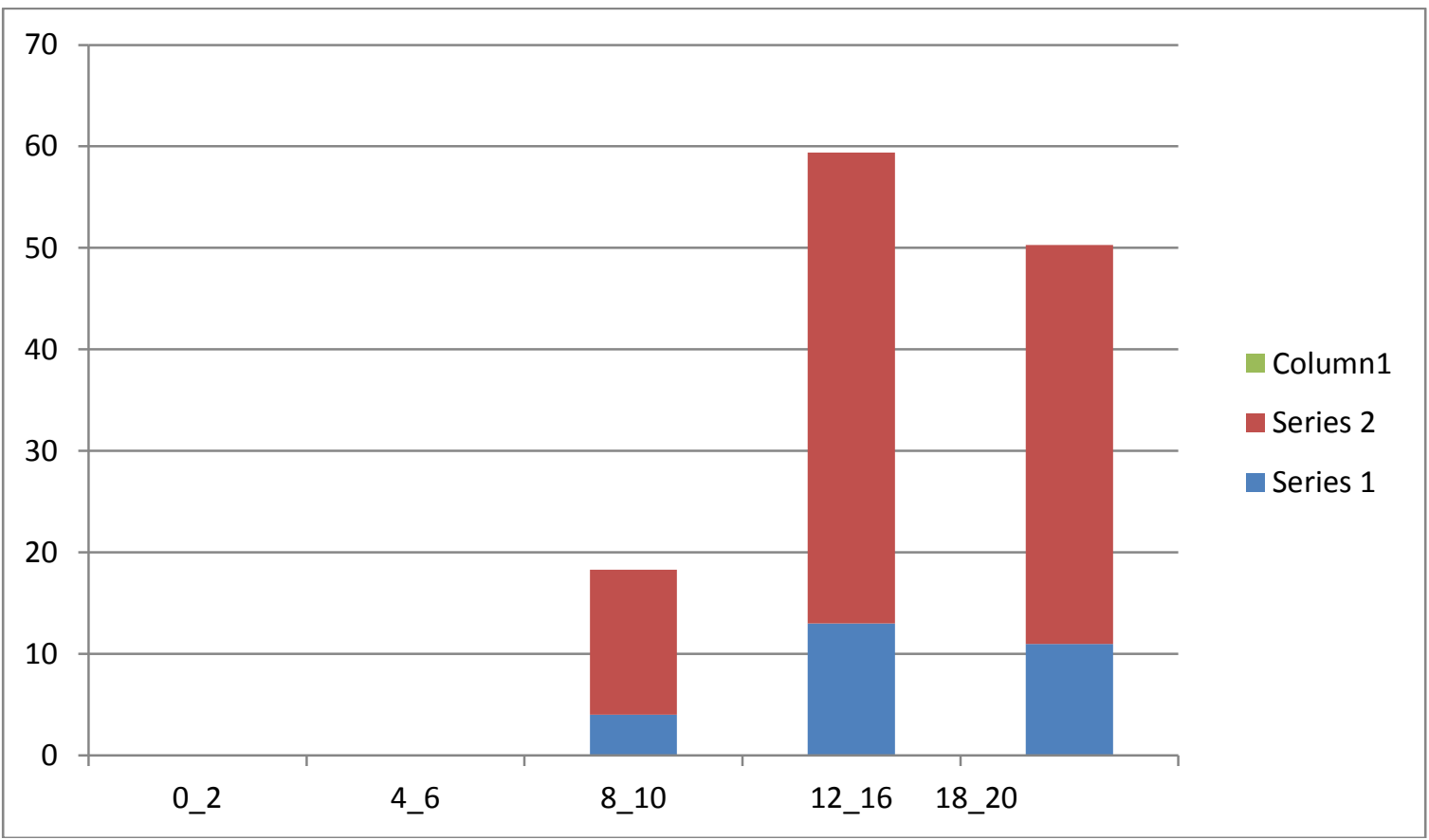

Table 3 shows distribution of pupils' scores in the pre-test. From the table it could be seen that the pupils scored in the ranges 0-2 and 4-6 respectively. Four pupils representing 30\% scored in the range 8-10. Thirteen pupils representing $46 \%$ scored in the range 12-16 and eleven pupils representing 39.3\% scored in the range of 18-20. The kind of activities that will help to improve pupils' performance in the topic energy transformation is demonstration method of teaching, where the teacher demonstrates for pupils to observe and the pupils also to demonstrate for the other pupils and the teacher also to observe.

\section{Conclusion:-}

The purpose of the study was to find out the effect of using demonstration method to improve basic stage two pupils performance on the topic building a simple electronic circuit at Juaben Presbyterian primary school. It is concluded that demonstration method is effective in improving the performance of basic stage 2 pupils on the topic simple electronic circuit.

\section{Recommendations:-}

Based on the major findings, the researcher has finally come out with the following recommendations and suggestions,

1. More teaching periods should be allocated for method of teaching science in the Ghana colleges of education so that student teachers will get enough exposure to lesson planning and presentation. 
2. Subject teaching should be introduce at basic 1-6 so that the right caliber of teachers will handle natural science and integrated science at the primary level of education.

\section{References:-}

1. Abbot, A. F. (2000) "Ordinary level Physics, London Heinemann Educational book LTD pp Publication 567618

2. Aseidu, P. (2005) "Integrated Science for Senior High Schools "Accra Ghana Aki - ola Publication

3. Assem, H. D. (2010) Science Methods for Colleges of Education (nEd) pp. 58 HARD Press, Kumasi

4. Folivi, L.E., \& Godman, A. (2001). New Certificate Physics. New Edition Longman Publisher pp 303-329 